\title{
Correlation of Blood Glucose Levels with Salivary Glucose Levels in Type 2 Diabetes Mellitus: A Comparative Study
}

\author{
Alekya Akasapu*, Usha Hegde and Priyanka Nitin \\ Department of Oral Pathology and Microbiology, India
}

Submission: May 09, 2017; Published: July 26, 2017

*Corresponding author: Alekya Akasapu, Post-Graduate student, Department of Oral Pathology and Microbiology, JSS Dental College and Hospital, Mysuru, India, Tel: +919741474409; Email: alekya.akasapu@gmail.com

\begin{abstract}
Diabetes mellitus is a complex multi-system disorder and is the most common endocrine disorder with potentially devastating complications that affects all age groups worldwide. Currently, a diagnosis of diabetes is achieved by evaluating blood glucose levels. Monitoring blood glucose at frequent intervals causes unnecessary discomfort and mental trauma to patients; therefore, a much simpler and non-invasive technique for the diagnosis and monitoring of diabetes is very desirable.

Materials and Methods: A total of 200 subjects were included (100 subjects in each group).Based on their clinical history, two groups were created; group I (Diabetic patients) \& group II (Healthy controls). Both the groups were screened for plasma and salivary glucose levels.

Result: The mean values of blood glucose were $115.230 \mathrm{mg} / \mathrm{dl} \pm 21.4$ for control group and $213.546 \mathrm{mg} / \mathrm{dl} \pm 68$ for diabetic group. The mean values of salivary glucose were $4.272 \mathrm{mg} / \mathrm{dl} \pm 2.23$ for healthy controls and $13.603 \mathrm{mg} / \mathrm{dl} \pm 5.599$ for diabetic group. The correlation coefficient between serum glucose and salivary glucose was calculated and the ' $r$ ' value was found to be 0.7686 , which was highly significant (P value 0.01 ). It is worth noting that the significance of the study group was much greater than that of the control group.
\end{abstract}

Conclusion: These findings suggest that saliva can be used as a diagnostic tool in assessment of blood glucose concentration. However further studies with larger and varied sample size are needed to strengthen our results.

Keywords: Diabetes mellitus; Saliva; Blood glucose; Salivary glucose

\section{Introduction}

Diabetes mellitus is a complex multi-system disorder which is characterized by relative or absolute insufficiency of insulin secretion and/or concomitant resistance to the metabolic action of insulin on target tissues. It is the most common endocrine disorder with potentially devastating complications that affects all age groups worldwide.

Type 2 diabetes mellitus is described as a global epidemic fuelled by population growth, ageing, increasing obesity, changing lifestyles and urbanisation. It is the fifth most common condition and the sixth leading cause of mortality amongst the elderly. The impact of diabetes is felt in both developed and developing countries, because of the high morbidity and mortality associated with its complications in renal, retinal, nervous and vascular system [1]. According to WHO, India has the world's most diabetic population followed by China $[1,2]$.
Currently, a diagnosis of diabetes is achieved by evaluating blood glucose levels. Monitoring blood glucose at frequent intervals causes unnecessary discomfort and mental trauma to patients; therefore, a much simpler and non-invasive technique for the diagnosis and monitoring of diabetes is very desirable.

For many years the presence of glucose in saliva has been a subject of debate and only few studies found correlation between blood and salivary glucose levels in diabetic patients. There are limited amount of studies evaluating the concentration of glucose in saliva and much controversy exists in the relationship between salivary and blood glucose levels [3]. Saliva offers distinctive advantages over serum because it can be collected non- invasively and by individuals with modest training. Furthermore saliva may provide a cost effective approach for the screening of large populations [1-6]. 
Hence the present study was conducted to determine the role of saliva as a diagnostic tool by estimating and correlating salivary glucose levels with that of serum glucose levels in the diabetic and non-diabetic groups.

\section{Materials and Methods}

The present study was conducted in JSS Dental College \& Hospital, Mysuru, India.

\section{Method of collection of data}

All patients with clinical history of diabetes and nondiabetes reporting to Hematology Laboratory-Dept. of Oral Pathology \& Microbiology, JSS Dental College \& Hospital for blood investigations, were included. Written consent of patients was obtained for saliva collection, salivary glucose level and random blood glucose level estimation and the procedures were explained to them. The ethical clearance was obtained from IEC (Institutional Ethical Committee).

\section{Inclusion \& Exclusion criteria}

Subjects of both the sexes who were 18 years of age and above were included. Subjects with any obvious oral lesions, those who were treated for any salivary gland disorders, subjects treated with radiotherapy of head and neck region, patients on medication for any other local or systemic disease other than diabetes mellitus were excluded from the study.

\section{Methodology}

A total of 200 subjects reporting to Hematology Laboratory for Blood investigations were included (100 subjects in each group). Based on their clinical history, two groups were created; group I (Diabetic patients -100) \& group II (Healthy controls $100)$. Both the groups were screened for plasma and salivary glucose levels.

\section{Estimation of blood glucose level}

Under aseptic conditions using a sterile disposable 25 gauge needle, intravenous blood was collected from the median vein. An anticoagulant (sodium fluoride) was added to test tube containing blood and centrifuged at $3000 \mathrm{rpm}$ for 10 minutes and the plasma was separated. To the glucose reagent, plasma was added and fed into the analyzer. The readings were noted and recorded from the semi-automated analyzer (ERBA 5 X).

\section{Estimation of salivary glucose level}

The patients were asked to rinse their mouth thoroughly with water. Unstimulated whole saliva was collected in a sterile container by asking the patient to expectorate into it over a period of 5-10 min till approximately $2 \mathrm{ml}$ of saliva was collected. Then sample was transferred to a disposable test tube and centrifuged at 2000rpm for 2-3 minutes and supernatant was separated. After addition of glucose reagent, the sample was mixed well, and the readings were recorded from the semiautomated analyzer (ERBA 5X).

\section{Statistical analysis}

The means and standard deviation were calculated for individual groups. These were then compared using ANOVA, Pearson's correlation coefficient, and regression coefficient. Data was analyzed using SPSS software (version 20.0).

Table 1: Descriptive statistics of salivary and blood glucose levels in diabetic and control groups.

\begin{tabular}{|c|c|c|c|c|c|}
\hline \multicolumn{7}{|c|}{ Descriptive Statistics } \\
\hline & N & Minimum Value & Maximum Value & Mean & Standard Deviation \\
\hline RBS- Controls & 100 & 64 & 204 & 115.23 & 21.44848 \\
\hline SGL-Controls & 100 & 1.5 & 14 & 4.272 & 2.23693 \\
\hline RBS Diabetics & 100 & 118 & 426 & 213.546 & 68.09567 \\
\hline SGL Diabetics & 100 & 5.1 & 36.8 & 13.603 & 5.59976 \\
\hline
\end{tabular}

RBS- Random Blood Glucose

SGL- Salivary Glucose Level

Table 2: Correlations between salivary and blood glucose levels among the diabetics.

\begin{tabular}{|c|c|c|c|}
\hline \multirow{3}{*}{ Saliva_Diabetics } & Saliva_Diabetics & 1 \\
& Pearson Correlation & $0.743^{* *}$ \\
\cline { 2 - 4 } & Sig (2-tailed) & 100 \\
\cline { 2 - 4 } RBS_Diabetics & N & $0.743^{* *}$ & 0 \\
\cline { 2 - 4 } & Pearson Correlation & 100 \\
\cline { 2 - 4 } & Sig (2-tailed) & 100 \\
\hline
\end{tabular}

${ }^{* *}$ Correlation is significant at the 0.01 level (2-tailed)

Pearson's correlation

$r=0.743$ 


\section{Result}

The mean values of blood glucose were $115.230 \mathrm{mg} / \mathrm{dl} \pm 21.4$ for control group and $213.546 \mathrm{mg} / \mathrm{dl} \pm 68$ for diabetic group. The mean values of salivary glucose were $4.272 \mathrm{mg} / \mathrm{dl} \pm 2.23$ for healthy controls and $13.603 \mathrm{mg} / \mathrm{dl} \pm 5.599$ for diabetic group (Table 1). The correlation coefficient between serum glucose and salivary glucose was calculated and the $r$ value was found to be 0.7686 , which was highly significant (P- 0.01). It is worth noting that the significance of the study group was much greater than that of the control group (Table 2). Therefore, there is a strong co-relationship between the serum glucose level and salivary glucose level among diabetics.

\section{Discussion}

Diabetes mellitus is a globally widespread metabolic disease caused due to hyperglycemia, which is the result of defect in insulin secretion, insulin action, or both. Chronic hyperglycemia may lead to metabolic dysregulation and failure of various organs, especially eyes, kidneys, nerves, heart, and blood vessels [5]. Presently, diagnosis of diabetes is achieved only by analyzing blood glucose levels, through venipuncture, which is invasive and is both physically and psychologically traumatic often causing pain and discomfort to the patient, especially children. Therefore, a simple, noninvasive, and painless procedure to detect the glucose levels is desirable. Keeping the above need in mind, the present study was pursued at estimating and comparing the blood and salivary glucose levels. Thus by comparison, it was aimed to establish a correlation between the glucose levels in blood and saliva, so as to evaluate the reliability of salivary glucose levels in diagnosis of diabetic condition.

Saliva is a wonderful adjunct, which can be used for early detection of many diseases. It has also offered some hope in estimating glucose levels as an alternative to blood and urine tests in diabetic individuals. Glucose is a component of blood that is exchangeable across the salivary gland epithelium in proportion to its concentration in blood [3]. If glucose level detection through saliva is developed, then it can detect the diabetic status of an individual non-invasively at an early stage. It can also prove to be more useful and effective in screening and follow up of a mass population.

In the present study quantitative estimation of the salivary glucose level in type- 2 diabetes patients was undertaken, to explore the possibility of using saliva in reflecting the glucose concentration in blood, thereby making the measurement of glucose easy and non-invasive. A total of 200 subjects were included in our study and were divided into two groups based on their previous clinical history as, Group 1: Diabetics and Group 2: Non-diabetics or healthy controls. The salivary and blood glucose values were compared between both the groups and the results evaluated were significant statistically. From these findings, it can be assumed that the movement of glucose into saliva is affected by diabetes mellitus condition. The results of this study confirmed that the salivary glucose is higher in diabetics than in the control group. This result is in agreement with several authors, Singh et al. [3], Jyrusta et al. [4] Darwazeh et al. [6], Swanljung et al. [7], Agrawal RP et al. [8], Panchbai et al. [9] compared the salivary and blood glucose levels between controlled and uncontrolled diabetics and the mean salivary glucose levels were higher among the uncontrolled group.

Similar study done by Satish et al. [10] and Abikshyeet et al. [5] showed positive correlation when fasting salivary blood sugar and salivary glucose levels were compared with that of glycosylated hemoglobin values among the diabetic and control groups.

Contrary to our study, Forbat et al. [11] used pure samples of parotid fluid rather than whole saliva and the salivary glucose levels did not reflect blood glucose levels. Amer et al. [12] revealed that the salivary samples of the non-diabetic control group subjects did not show presence of glucose even in the slightest concentrations, while that of diabetic group showed significant concentrations in the saliva.

\section{Conclusion}

The rise in blood glucose value, showed a proportional increase in the concentration of glucose in the saliva and this finding was statistically significant. Thus our study positively indicates that saliva can be used as an alternative to blood for diagnosing and monitoring diabetes mellitus status. However, the implications of the study are still at an infant stage, as there are few limitations in our study. For instance, a lot of factors are known to influence the secretion of saliva and its constituents. Secondly similar studies with greater sample size and stringent criteria will help in developing standard salivary glucose values in diagnosing and monitoring diabetes mellitus.

\section{References}

1. Manfredi M, McCullough MJ, Vescovi P, Al-Kaarawi ZM, Porter SR, et al. (2004) Update on diabetes mellitus and related oral diseases. Oral Diseases 10:187-200.

2. Shashikumar R, Kannan R (2010) Salivary glucose levels and oral candidal carriage in type II diabetics. Oral Surg Oral Med Oral Pathol Oral Radiol Endod 109(5): 706-711.

3. Singh (2014) Comparison of Salivary and Plasma Glucose Level in Type II Diabetic Patients' Res Adv Dent 3(1): 263-268.

4. Jurysta C, Bulur N, Oguzhan B, Satman I, Yilmaz TM, et al. (2009) Salivary Glucose Concentration and Excretion in Normal and Diabetic Subjects. J Biomed Biotechnol 2009: 430426.

5. Abikshyeet P, Ramesh V, Oza N (2012) Glucose estimation in the salivary secretion of diabetes mellitus patients. Diabetes Metab Syndr Obes 5: 149-154.

6. Darwazeh AM, MacFarlane TW, McCuish A, Lamey PJ (1991) Mixed salivary glucose levels and candidal carriage in patients with diabetes mellitus. J Oral Pathol Med 20(6): 280-283.

7. Swanljung O, Meurman JK, Torkko H, Sandholm L, Kaprio E, et al. (1992) Caries and saliva in 12-18 years old diabetics and controls. Scand J Dent Res 100(6): 310-313. 
8. Agrawal RP, Sharma N, Rathore MS, Gupta VB, Jain S, et al. (2013) Method for Glucose Level Estimation by Saliva. J Diabetes Metab 4: 5.

9. Panchbhai AS, Degwekar SS, Bhowte RR (2010) Estimation of salivary glucose, salivary amylase, salivary total protein and salivary flow rate in diabetics in India. J Oral Sci 52(3): 359-368.

10. Satish BN, Srikala P, Maharudrappa B, Awanti SM, Kumar P, et al. (2014) Saliva: A tool in assessing glucose levels in Diabetes Mellitus. J Int Oral Health 6(2): 114-117.
11. Forbat LN, Collins RE, Maskell GK, Sönksen PH (1981) Glucose concentrations in parotid fluid and venous blood of patients attending a diabetic clinic. J R Soc Med 74(10): 725-728.

12. Amer S, Yousuf M, Siddqiui PQ, Alam J (2001) Salivary glucose concentrations in patients with diabetes mellitus: a minimally invasive technique for monitoring blood glucose levels. Pak J Pharm Sci 14(1) 33-37.

Your next submission with Juniper Publishers will reach you the below assets

- Quality Editorial service

- Swift Peer Review

- Reprints availability

- E-prints Service

- Manuscript Podcast for convenient understanding

- Global attainment for your research

- Manuscript accessibility in different formats

(Pdf, E-pub, Full Text, Audio)

- Unceasing customer service

Track the below URL for one-step submission https://juniperpublishers.com/online-submission.php 